\title{
Dis/Ability Arts and Systemic Innovation in the UK and Sweden
}

\author{
Green, Kai Roland
}

Published in:

Journal of Social Entrepreneurship

DOI:

10.1080/19420676.2020.1788122

Publication date:

2022

Document Version

Peer reviewed version

Citation for published version (APA):

Green, K. R. (2022). Dis/Ability Arts and Systemic Innovation in the UK and Sweden. Journal of Social

Entrepreneurship, 13(3), 366-389. https://doi.org/10.1080/19420676.2020.1788122

\section{General rights}

Copyright and moral rights for the publications made accessible in the public portal are retained by the authors and/or other copyright owners and it is a condition of accessing publications that users recognise and abide by the legal requirements associated with these rights.

- Users may download and print one copy of any publication from the public portal for the purpose of private study or research.

- You may not further distribute the material or use it for any profit-making activity or commercial gain.

- You may freely distribute the URL identifying the publication in the public portal.

Take down policy

If you believe that this document breaches copyright please contact rucforsk@kb.dk providing details, and we will remove access to the work immediately and investigate your claim. 
Dis/ability Arts and Systemic Innovation in the UK and Sweden Kai Roland Green

Roskilde University, Denmark

Email: krgreen@ruc.dk

Tel: +4522346143

https://orcid.org/0000-0003-3192-9149 


\section{Dis/ability Arts and Systemic Innovation in the UK and Sweden}

Abstract: This paper explores the normative and epistemic effects of dis/ability arts organizations in the UK and Sweden, when theorised as systemic innovations. With the development of a discourse for the Arts and Health movement and Art Entrepreneurship, a gap emerges for socially entrepreneurial ventures whose innovation value lies beyond the well-engrained parameters of 'work integration' for persons with dis/abilities. Using an aesthetic philosophy of kynicism (Sloterdijk 1987), this paper identifies the disruptive potential of three case-study organisations within the settings of health, social care, and the arts. Data from interviews and/or presentations with managers from Moomsteatern (SE), Teater Interakt (SE), and Breathe Magic (UK) are compared and contextualised within a 'social model' of dis/ability, against which the existing discourse of innovation is found wanting. The resulting discussion finds epistemic validations of the speech, expertise and bodily autonomy of persons of dis/abilities within hybrid organisational settings.

Keywords: disability; aesthetics; social entrepreneurship; systemic innovation; arts 


\section{Introduction}

The stigmatization of persons with dis/abilities ${ }^{1}$ has been geographically widespread, historically long lasting and vast in its de-legitimation of knowledges and experiences. Examples of formal progress - such as the ratification of the UN Convention on the Rights of Persons with Disabilities in 2007 - have not entirely eradicated public sentiments of this group as 'freaks of nature, objects of pity, and burdens to society' (Phillips 2001, 195). Technological innovations in this area, in the form of wheelchairs, ramps and accessible toilets, have aimed for parity of access to public space by integrating some key additional needs of persons with dis/abilities. Yet, societal developments by and with dis/abled people have rarely been considered social innovations or integrated into the research field of social entrepreneurship.

More empirical examples of social innovations which validate the experiences of marginalized groups are clearly needed in a research field which investigates radical shifts in 'basic routines, resource and authority flows, or beliefs of the social system' (Quilley 2012, 222). Where they appear, social innovations are theorized as practices of selfactualization that generate bridges toward greater 'social cohesion' (Cancellieri et al. 2016, 7). Distinctively, social innovations do not rely on top-down services which may hold restricted understandings of what is possible for marginalized groups. When such epistemic validations unlock additional value across multiple sectors (public, civic and private), they can be described as systemic innovations, with the potential to be globally transformative (Newey 2018). Yet, research which illustrates dis/ability initiatives innovatively operating in this cross-sectorial way has been collectively unimaginative in its scope and analysis.

This paper builds on the critical and reflective potential of the social entrepreneurship research field by examining an under-researched area of organisational, aesthetic and socially-entrepreneurial scrutiny: dis/ability arts organisations. The research

\footnotetext{
${ }^{1}$ Whilst discussion of different models for understanding dis/ability takes place throughout the paper, a central definition of the term may guide the reader. This paper understands dis/ability as "loss or limitation of opportunities to take part in the normal life of the community on an equal level with others due to physical and social barriers" (Dis/ability Peoples International 2012). The addition of the oblique (/) emphasizes that such barriers do not preclude the positive abilities stemming from an impairment.
} 
design aimed to answer the question "How do dis/ability arts initiatives navigate and disrupt social structures to perform systemic innovation?". Discursively, how the arts and creative industries defy their expectations as businesses and machines of social capital is underdeveloped within social entrepreneurship studies. In the development of projects for alleviating social inequality, "innovation" is more typically used as a catch-all term for creativity and design (necessary but not sufficient features for understanding the arts sector). In parallel, the central concepts of a hybrid discourse like social entrepreneurship are viewed with suspicion within arts scholarship produced in Europe's neo-liberal era. The role of the aptly named 'artrepenaur' (Harvie 2013, 63) has been resisted from within artist circles for its assumption that the arts must prove their values in terms of economic growth at the expense of state-support. When straddling multiple sectors, social entrepreneurship is not immune to the historic conflicts between the arts and commercialism, yet is a key site for the melding of artist practices (such as visual art, music, theatre and dance) with addressing complex social problems.

After sketching a background to the conceptual and organisational linkages between the creative industries and social innovation, this paper will report on a threeorganisation case study of dis/ability arts initiatives. The possibilities enacted by these creative initiatives for systemic social innovation will then be unpacked in terms of their ability to disrupt structures, illustrated by the aesthetic theory of kynicism. The concluding discussion assesses access to knowledge and access to a meaningful platform for speech and listening enabled by dis/ability arts organizations, against the backdrop of an innovation discourse which can easily miss the nuances of 'social-service innovation[s]' (Svensson and Bengtsson 2010) which affect whole systems of health and social care.

\section{Background: Social Enterprise and the Creative Industries}

Social innovations within the creative industries sector reflect the so-called 'social turn' in the output of cultural institutions, where the 'infrastructural operations of performance' (Jackson 2011, 29) are laid bare by theatres, museums and art galleries in pursuit of greater participation or diversity from audiences (Bishop 2012). The synergy between artistic outputs as both creative/expressive and economic reflects similar tensions within the prevailing social entrepreneurial rationality (Barinaga 2013) which justifies itself by divergent accounts of contributing to the social. Typical to socially-engaged performance 
work is a reconfiguring of public space: live performances taking place outside the mainstream organising structures of venues (which may foster lack of access by marginalised groups) allow a rippling affect to 'other areas of society spatially and attitudinally' (Onyx et al, 2018). The implicit assumption of citizen inclusiveness behind the notion of public space makes the presence and action of those from socially marginalized groups in public space all the more impactful.

From the side of the creative industries influencing social innovation initiatives, sectors like Health increasingly incorporate the performing arts into their practices. Echoing Charles Edward Winslow's definition of public health as the 'science and art' of preventing disease (Parkinson and White 2013), initiatives such as the 'arts in hospitals' movement (Macnaughton et al. 2005, 332) have gradually built an evidence base of practices that includes theatre and music performance in hospitals, diversified health to not just include biomedical models of disease-prevention (Sigurdson et al. 2015) and legitimated professional roles such as hospital arts coordinators (Aston 2009). Recent examples include the use of reflective art forms in the training of doctors to build empathic responses to crisis situations, such as Clod theatre's Performing Medicine programme.

More subtly, the influence of place-based socially engaged art forms can be seen in the discourse of patients on journeys through their health care: the UK's Department of Health has frequently spoken of 'health action zones' (Dooris 2005, 366) to connote this breaking down of organisational barriers. The performing arts use aesthetics against the background of a conventional space - whether literally, in the case of actors dressed as nurses performing in hospital wards, or with a more symbolic contrast between space and action. As Sigurdson et al. notes, Swedish healthcare attempts a strong correlation between the 'Illness environment' that a patient experiences in hospital and their 'healthy environment' at home (Sigurdson et al. 2015, 85). Cultural interventions which use space as a tool direct audiences to see spaces not as they literally appear, but as the backdrop to something imaginary being performed. Thus, when Jensen et al. speak of the arts '[t]ransforming the illness experience' (Jensen et al, 2016, 180), is conveys both that a space can become an 'experience' with performance and that this is triggered by acts of theatrical transformation. 
The language of entrepreneurialism is present in the performing arts, but with predominantly individualist rather than collectivist tones. Artist-entrepreneurs have been observed in trends toward financing their own creative work and developing additional business-skills that re-contextualize their creative practice in terms of additional value creation (Brown 2005, 160). The self-actualizing spirit of the entrepreneur has led to a number of entrepreneurship education programmes involving the arts. Yet, whilst there have been experiments in combining arts management with a 'community engaged perspective' (Clark and Stewart, 2012) in North America, some published work on promoting entrepreneurship in the arts (through a National Council in the UK) manages to not mention 'social entrepreneurship' even once, as in Brown 2005. A pragmatic and imaginative language for arts initiatives running as social enterprises - operating in the creative industries but with an aim for societal betterment - appears lacking. Thus, when Harvie reflects a distrust of the 'artrepreneur' who 'works privately for her own advantage' $(2013,63)$, it seems legitimate to question if this stems from a suspicion of the non-social work of the entrepreneur, or the artist as not socially engaged.

Artists, as Jackson notes $(2011,18)$, consider "the social" both figuratively and literally in their work, suggesting that their practice may be broadly social in its contribution rather than imagining specific individual or groups benefitting. The entrepreneurial side of the creative industries still reveals barriers against harnessing artistic practice for social good through enterprise: Brown notes that 'creative businesses do tend to "cluster" around centres of academic and creative excellence' (Brown 2005, 161). If arts and business align in areas of high cultural capital and prestige, as Brown's essay suggests, it could be argued that these are highly likely to be spaces with a higher socio-economic average. At the very least, artists working in this environment may be cushioned against a literal view of social marginalization, encouraged to retreat to a figural or symbolic sense that their work could be put to additional social uses. For those with a profound faith in the arts as capable of social transformation and often collaborative (perhaps more obvious in the performing arts than the visual arts), it is disconcerting that the social entrepreneurship field features few arts-based enterprises.

Researchers in health and social care have also noted that many of those considered 'entrepreneurs' in their field do not self-identify as such, but rather describe themselves through the lens of another professional identity (Kovalainen and ÖsterbergHögstedt 2013, 25). Observations such as these expose the socially constructed nature of 
professional categories, under which workers utilize competencies for different tasks, perhaps create new opportunities for themselves within a professional role, or apply the skills from one professional discourse to another. Harvie hints at a political reading of this situation when speaking of how 'neoliberal capitalism infiltrates and reconfigures structures, practices and subjectivities' (Harvie 2013, p.65). The individualism stemming from a neo-liberal economic context encourages workers to see themselves in more fixed categories than their lived experience truly accords with. Neither artists and entrepreneurs may not know each other to be so, purely on the basis of their validated titles.

\section{The Social Model of Disability}

For a contender in linguistic (social) innovation, look no further than the social model of dis/ability. This movement understands dis/ability as a phenomenon not contained within the agent in question - rather, that people are dis-abled by a world that does not accommodate their needs. This radical shift of responsibility acknowledges that all those who do not consider themselves dis/abled are, nonetheless, only 'temporarily abled' (Goodley 2014). Citizens may experience manoeuvring through city spaces but not encounter dis-abling elements, such as the lack of a ramp to enter a building. This lack of physical experience with dis/ability is, for advocates of the social model, part of reenforcing the entire concept of dis/ability, which becomes a verb ascribed to society's arrangements rather than to individuals. In other words: stairs to a building without a ramp dis-able users of a wheelchair; a rule which enforces 'no talking' in an art gallery dis-ables a guest who has a neurological condition which restricts them from involuntary, verbal expression, such as Tourettes Syndrome.

Applied to social innovation, this perspective encourages a temporarily ablebodied public to view the accessibility and equality of their city in a revelatory way. Yet, innovation studies rarely deal with the imaginative potential of dis/ability to critique and orient societal arrangements; instead, dis/ability is a position to be innovatively managed. Market-oriented social enterprises are seen to reflect professional empowerment for individuals with physical or mental impairments (Gidron, 2013), and the dominant model of a 'work integration social enterprise' (WISE) establishes valued social outcomes which - even when divided into micro, meso and macro by De Ruysscher et al., (2017) - focus 
almost exclusively on dis/abled people working to improve their own lives. Models such as the WISE appear to leave little room for a language of dis/ability's creative potential as a producer of innovation, for underscoring a perspective, like that of British artist Jess Thom, that Tourette's Syndrome can be a 'crazy language generating machine' (Amit, 2015) which accesses an otherwise-untapped creativity.

Criticisms of the social model within dis/ability studies have fruitful parallels to questions of agency within social innovation. In a series of awards by the European Network for CSR and Dis/ability in 2014-2015, for example, an 'Innovative electric wheelchair' was given special recommendation with the company commenting: '[w]hile sports cars or beautiful motorbikes have replaced horse carriages in less than 100 years, the wheelchair has stayed the same' (Tussy et al. 2015, 9). The statement treats the wheelchair as an innovative development of a means of transport just like the car. Yet, an alternative reading of the development of car could identify it as a systemic innovation which transformed 'the nature of transport' and required 'a whole raft of complementary innovations in terms of products and services' (Davies et al. 2012, 4). Beyond a 'change of scale', the car challenges contexts, practices and structures by its emergence. Wheelchair development, by contrast, continues to place responsibility onto an individual to navigate the spatial and practical relationship between their impairments and society.

Just as the social model has been described as erasing 'not just the body... but also the mind' (Goddard 2017) of a dis/ability body-politic (by locating responsibility in amorphous societal structures or 'barriers' rather than validating individual experiences of impairment), so too the criteria of outwardly critiquing and exposing societal narratives is disputed in social innovation research. The concept of 'symbolic violence' (Dey, 2010) is not entirely accepted in the domain. Comparing the dispute around models in disability studies to conflicting assumptions of agency in social innovation encourages the field to provide more critical perspectives on its epistemological claims, such as that "people are competent interpreters of their own lives and competent solvers of their own problems" (Mulgan 2007), leav. How clearly articulated may we expect innovative solutions to be if the responsibilities of individuals are reinforced above that of systems which constrain and define the individual as 'disabled'? 


\section{Dis/ability arts case studies}

As a subfield of enquiry within research on the creative industries, dis/ability arts encompasses work by artists and performers, whose physical condition may be regarded as 'able-bodied' or not, as well as makers working in the pursuit of a dis/ability cause. Artistic outputs include live performances in entertainment venues, patented products which support accessibility, or work-programs designed around specific needs. As entrepreneurs, dis/ability artists provide solutions to existing problems by revealing previously dormant gaps in the overlapping systems of health and public policy, as well as generating commercial and social value for smaller and larger groups (Kitching 2014). To critically question how society's arrangements (geographic, political and moral) conspire to co-create the possibilities for being dis/abled is to 'ask serious questions about the social world' (Goodley 2010, p.xi). The following organisations were analysed for the serious questions they pose.

\section{Moomsteatern}

Moomsteatern are a 'professionally integrated theatre' company (MOOMSTEATERN Booklet 2012, 1) of both actors with and without intellectual dis/abilities, based in Malmo, Sweden. The company began in 1987 and became recognized as a full-time employment opportunity for people with intellectual dis/abilities in 1992 (MOOMSTEATERN Booklet 2012, 2). There are generally five to seven full-time performers in the company, many of whom have been supported to train at the National Theatre Academy of Sweden and are members of the Swedish Actors Guild. The company produce two or three productions per year, with 60 to 70 performances every year in Malmo.

Beyond Malmo, Moomsteatern tour internationally and are members of Europewide collaborative partnerships. One such example - Crossing the Line - is a co-operative project between three leading theatre companies working with artists with intellectual dis/abilities, sponsored by the EU Creative fund. The project included skill-sharing residencies and partner meetings with the respective companies in Sweden, France and the United Kingdom culminating in a theatre festival in Rouboix, France, in January 2017 (Todd 2016). 


\section{TeaterInterakt}

Teaterinterakt began in 2005 as an independent theatre company in Malmo, Sweden, working in collaboration with street theatre La Runfla in Buenos Aires (Argentina), Dah Teatar in Belgrade (Serbia) and The National Theatre of Ulaan Baatar (Mongolia) (TeaterInterakt - Bakrund n.d.). The company works with marginalized groups whose voices are not often represented in art contexts, or society more broadly, including elderly people, dis/abled people and recent migrants to Sweden.

\section{Breathe Magic}

Breathe Magic is an intensive therapy programme developed by Breathe Arts Health research: a non-for-profit social enterprise who provide healthcare programmes to the British National Health Service (Breathe AEHR 2016). The programme works with children aged 7-19 years old (ibid.) who have hemiplegia - a motor impairment to the hands that results in a difficulty manipulating objects or performing some precise, physical tasks (Fancourt 2016) - by teaching them magic tricks. The tricks are designed by magicians from The Magic Circle and taught to the children in 60 hours of intensive therapy, delivered 1-to-1 along with occupational therapists (Breathe AEHR 2016). The initiative was Winner of NHS England's 'Innovation Challenge Prize for Rehabilitation' in 2016.

\section{Methods and Materials}

Initiatives from Breathe Magic, TeaterInterakt and Moomsteatern were used as an exploratory case-study for how the intersection of dis/ability and arts practices can constitute and challenge operations within social systems. The criteria applied to selecting these cases were that each was a revenue-generating organization whose operations involved close interaction with dis/abled people, and involved theatrical performance. The resulting group of cases presented diversity in terms of culture (from the UK and Sweden), in the particular impairment of the practitioner or beneficiary (physical loss of 
motor function and neurodevelopmental condition) and in organizational arrangement (social enterprise, independent and mainstream theatre companies). As Polenis remarks, 'case study method's support for theory building is particularly useful in areas where existing theoretical and conceptual frameworks are inadequate' (Polenis 2015, 537). This was the basis for the decision to use three organisations to more viably understand the intersection of dis/ability, arts and social policy.

The methodological criteria for operating within the chosen research paradigm includes 'trustworthiness, credibility, transferability, confirmability' (Denzin and Lincoln 1994, 27), qualities that were strived for in the following ways. By the use of interviews, participants (all figureheads of their organisation) were able to speak freely on subjects around the central topics of enquiry. Dominant themes were identified on the basis of a literature review to give credibility in the various disciplines that intersect around dis/ability and the Arts and Health movement. Confirmability can be challenged in an interpetivist paradigm (as one researcher's interpretations will be different from another) but an extensive coding process reveals the steps in the process that lead to the analysis. The use of multiple organisations, into a case-study, also supported confirmability. Priority was given in discussion to subjects that appeared in the two or three of the casestudy interviews.

Semi-structured interviews were performed with leaders at two organisations (Moomsteatern and TeaterInterakt) during March and April 2018, with a third organisation represented in data analysis via the transcript of a performance/lecture (Breathe Magic) given at the event 'Arts and Health Conference and Showcase for health decision makers' in February 2016. Fieldnotes from two conferences - on the theme of Arts and Health in the UK (in April 2018) and Arts and Entrepreneurship in Denmark (April 2017) - were used as added context and included in the coding. Once data was collected, 'emergent coding' (Ponelis 2015, 543) was used to let the data guide the establishment of themes. The coding focussed on repetitions of ideas and the most striking responses in the context. Participants were asked questions on the themes of their relationship to health, to creative processes, to the societal themes of their work, and the influence of the business structure on their outputs.

The research process did not involve interviewing, or participating with, any dis/abled people directly. None of the organisational leaders described themselves as having a dis/ability during our interactions. The principle from within dis/ability activism 
- 'nothing about us without us' - is a legitimate challenge to research in this area, encouraging studies to explicitly reflect on their culpability to misrepresentations. The exact intentions of this study, however, were to explore the ways that each organisation approached dis/ability conceptually, aesthetically, and through procedural interaction with health and social care systems, among others. Given this focus, the study explicitly does not discuss or the success criteria for the organizations, or the legitimacy of their representations to community stakeholders. Such focuses would require a different research design which explicitly drew upon the lived-experiences and expressions of dis/abled people.

\section{Ontology and Epistemology}

The analysis of this study follows the social model of dis/ability by making a distinction between impairment and dis/ability within a social constructivist ontology. The scales of relativism drawn from this perspective are varied: collective social understanding is formed both at a local level, horizontally through networks, and part of world-wide interconnections of knowledge. This study takes a broad scope view of collective understanding: as Goodley argues, dis/ability can be seen as 'a social process that intimately involves everyone who has a body and lives in the world of senses' (David 1995, in Goodley 2014, 10). Crucially, this definition is both micro and macro in scale theorizing that processes (of knowing) are influenced by shared human experience both as a populous and as an individual, sensing body. The particular balance of individual, phenomenal experience and collective social construction is explored through the use of a critical inquiry.

In exploring the spaces, themes and concepts of contention between the empirical experience of dis/ability arts practice and the discipline of social entrepreneurship, this study uses an interpretivist epistemology. Quoting Leitch, Hill, \& Harrison (2010), Ponelis identifies an intereprivist epistemology as 'based on a life-world ontology that argues all observation is both theory- and value-laden and investigation of the social world is not, and cannot be, the pursuit of a detached objective truth' $(2015,538)$. This precipitates the need to reflect on the lineage of ideas and knowledge-streams when they occur, which is particularly important for putting research fields such as aesthetics and organisational studies against each other, and thus must indicate the context of concepts 
as they are described. The question that this study aims to address also pre-meditates the drawing of hypothetical boundaries around phenomena - so as to define the research and practice field for a specific subset of organisations - but must therefore reflect on this 'boundary drawing' as highly subjective.

\section{Kynicism}

At the harder end of a social constructivist ontology, it is possible to uphold that collective experiences of the world are not so naïvely or arbitrarily arranged, but rather as a result of dominant ideologies. It is from this position that critical theory emerges, as a means to analyse paradigms of thought and justification which systemically oppress certain groups in society. The theory of kynicism derives from Ancient Greek philosophy, was principally revived by Peter Sloterdijk, and emerged in the context of seeing ideology as something which performs 'exclusion as a form of symbolic violence' (Allan 2004, 34). Individuals who are part of marginalized social groups are denied opportunities or access to the instruments of navigating societal structures.

Kynicism begins from the position that a world beyond ideology is not possible to more than glimpse at. Philosophers such as Sloterdijk are pragmatically interested in skipping "the rigged game of "discourse" and "[forcing] ideology to do its own unravelling' (Allan 2004, 38). Kynicism is an individual's critical stance against a world order, like cynicism, but is distinctive for its joyous, sensual and bodily approach. Kynicism reaffirms the importance of the body as the primary site from which all actions emanate, including theorising, judging and deciding. For Sloterdijk, the body's processes have been devalued as a site for knowledge and value by a 'thinking limited to the head' (Sloterdijk 1987, 102). Natural bodily processes appear absent from the realm of philosophy.

The contemporary significance of kynicism is to acknowledge that, whilst philosophy may not be the dominant language in which society is discussed and policy is made, cynicism remains the dominant intellectual position for individuals against systems. The body remains de-valued. Kynicism re-affirms the whole body as a 'kind of argumentation' (Sloterdijk 1987, 101), rejects the dominance of language as the interlocutors tool, and emphasizes natural life processes against ideological restriction: 
Ancient kynicism begins the process of naked arguments from the opposition, carried by the power that comes from below. The kynic farts, shits, pisses, masturbates on the street, before the eyes of the Athenian market. (Sloterdijk 1987, 103)

The significance of 'from below' signals the importance of the theory for subjects where systemic power and individual bodies are discussed together, such as within dis/ability studies. The phrase echoes both (lower) places of bodily privacy and the political significance of resistance from those suppressed by hierarchical systems. Kynicism plots how individuals relate to systems through 'subversive tactics' (Allan 2004, 38) presenting disruptions to social convention, and impacting those who uphold it. Sloterdijk's identifies the resistant quality of 'cheekiness' in kynicism - a quality which was always a method of constructively critiquing hegemonic ideas. Cheekiness was a 'productive aggressivity’ (Sloterdijk 1987, 103) against established orders.

Whilst Sloterdijk's theory of Kynicism was created in the context of an alternative to the lethargy of postmodernist cynicism, its broader applications have recently included questions of aesthetics by dis/ability theorists (Allan 2004; 2005). As Allan accounts for, a determined group of dis/ability artists produce forms which "dis-comfits able-bodied people by forcing them to examine their own normalizing and disablist attitudes" (Allan 2004, 41). This work develops Sloterdijk's linkage between kynicism and aesthetics on the basis that Art was a key battleground for how kynicism sought to refute the 'idealism' which pervaded the intellectual environment of the time, an idealism which 'justifies social and world orders' (Sloterdijk 1987, 104) with its theoretical ideals. Notions of aesthetic perfection - in the form of Gods and Saints as subjects, or the style which sought to faithfully reproduce reality, in the Naturalist movement - were met with work which 'wanted to embody the rights to existence of the excluded low elements with body and soul' (Sloterdijk 1987, 108). A return to sensual reality, the body in its imperfect material form, is an allegory for readdressing systemic repressions of those whose bodies have never fitted the created 'ideals'. This has been the potential of the kynicist intellectual position for dis/ability artists.

\section{Results}


The following themes emerged as points of systemic disruption in the analysis of Breathe Magic, TeaterInterakt and Moomsteatern: Validations of Dis/Ability; Cost-Effectiveness; Holistic Views of Health; The Role of Intermediaries; Care in the Health System.

\section{Validations of Dis/ability}

All three organisations describe their output in terms of acknowledging the knowledge and experience of the dis/abled people that they work with. In introducing a young boy who has been through the intensive therapy sessions at Breathe Magic, magician Richard McDougall explains to the audience: 'So, what we need for this is an expert in their field, because this is the mystery that does take over many, many months to practice, to perform' (GREEN 2019, 6-7)

The language of expertise represents a high accumulation of capital in a currency that is valued by a particular domain. The issue is crucial in considering systemic innovation because, as was explored during the Arts and Health Conference, institutions which attempt to build artistic expertise - such as Art schools - are also grappling with these issues in how to reconcile any social obligations with artist ones. In the context of exploring the health-benefits and innovations of artistic practice, one key question opening the conference was 'What is a Conservatoire trying to do?' (GREEN 2019, 42) - an ontological question prompted by an acknowledgement that strictly aesthetic criteria may be counter to more socially equalizing aims.

For Moomsteatern, the audience's conventional experiences of theatre (in which they are 'receivers' of what happens on stage) sometimes clash with their reactions to dis/abled people outside of the theatre. As they explain, some audience members are 'not willing to be receivers. They want to be senders back, because that's the way to treat a person with dis/ability' (GREEN 2019, 15). When this resistance is challenged, the audience is able to give themselves: 'a chance to experience or learn something, from a person who is, outside the theatre, is living a very marginalized life' (GREEN 2019, 15).

In the send/receive dichotomy, the sheer act of being listened to, as a person with a dis/ability, is a recognition that their words have value as the voice of someone who normally experiences marginalization. Similarly, in the language of valuing work, 
Moomsteatern's actors 'work 40 hours per week' (GREEN 2019, 13) as part of a bespoke programme that combines traditional employment with particular support functions around intellectual dis/ability. There is a resistance, however, to adhering to all expectations of these programme structures, particularly in how they constitute the validity of specialisation - given the expectation that someone with a dis/ability 'should be involved in everything' (GREEN 2019, 14) in an organisation. From the perspective of the theatre industry, the workers are described as 'actors', with a series of strong employment conditions which would be regarded as unusual in many theatre contexts they are 'fully employed, and as I know we are the only theatre in the world, with who has gone that way and succeeded' (GREEN 2019, 18).

Whilst dis/ability is often seen to require layers of active, societal support, the organisations describe their workers/actors in terms of a freedom from restriction and appear to prioritise the autonomy that dis/abled people can have over their own bodies. Moomsteatern describe the independent contribution that can be made by their company members in terms of personal, societal and financial development, as well as a reduction of pressure on systems, noting that employment means the actors: 'have their salaries, they pay taxes, they have better wellbeing, less problems, medical and psychological and whatever, and they become independent persons' (GREEN 2019, 27). References to wellbeing, as well as less burden on medical and psychological services, are spoken of in the same breath as employment and taxes. These various notions of independence do not suggest a separation from social systems but rather, in the case of employment, a greater immersion within them.

A particularly powerful theme that arises within the notion of independence is the more specific sense of bodily autonomy and privacy. In the case of Breathe Magic, increased motoric skills for the children promotes their ability to be self-reliant, which comes out particularly in relation to privacy:

Now, that feels like a small thing, but if you imagine a young child reaching puberty, who can't go to the toilet on their own because they can't pull up their own pants, you know this is very serious stuff (GREEN 2019, 6).

Moomsteatern identify similar difficulties of bodily care yet, appropriately due to the different nature of intellectual and physical dis/abilities, account for the issue more in terms of a personal capability: 
So, my experience with my colleagues with intellectual dis/abilities is that they don't have, really, the capability to take care of their body. You don't see them as much in the gym, on the tennis court, and things like that (GREEN 2019, 12).

In a flipping of the dynamic, Moomsteatern also appear to have interest in bringing the realities of bodily life - often private - to the audiences of their productions. The Artistic Director notes that they 'have had actors who has have had serious flu and we have put buckets all around outside the stage, and then they go out, play and [sound of person being sick]' (GREEN 2019, 11).

All three organisations account for ways in which their work promotes a greater understanding of the lives and experiences of dis/abled people - either through an unconcealment of dis/abling barriers which principally affect the group, or through ways to embrace the situations shared between temporarily able-bodied people and dis/abled people. Breathe Magic explain the physical impairments of the children that they work with in terms of everyday tasks, that 'everyday activities that you and I might take for granted are incredibly difficult often impossible for this group of young people' (GREEN 2019 , 5). The notion of 'taking for granted' recognises an experiential gap: certain activities are so ubiquitous that we may not appreciate their challenges to certain people.

\section{Cost-Effectiveness}

Breathe Magic, TeaterInterakt and Moomsteatern variously account for their viability in terms of 'cost-effectiveness' and differently stress the link between organisational form and identity. Breathe Magic's Founding director emphasises the work as a 'a costeffective program' (GREEN 2019, 5), with a more subtle reference coming from magician Richard McDougall, after using his magic skills to seemingly duplicate a red ball: 'So, now, you have two for the price of one, which means nothing to you, but it's very cost-effective for me' (GREEN 2019, 6).

McDougall's joke plays off the idea of a growth agenda to which the arts have historically had a complicated relationship. The same notion is suggested by Tim Joss' comments at the opening of the 2018 Arts and Health conference that the concept of 'scaling-up' is predominantly new for the Arts (GREEN 2019, 45), the localism of whose 
projects have not always been amenable to replication. McDougall's analogy of the red balls with money reflects the qualitatively different use of dominant currencies within the arts - giving a new sense to what 'cost-effectiveness' could mean when applied to other, non-financial outcomes.

The economic viability of arts practitioners is reflected in how Moomsteatern speak of their company's expectations around health management:

I think if you should measure the actors who are working here in health issues - how many when are they sick, when, how much - you would get fantastic numbers. Because our actors isn't sick [...] there is an attitude here, at theatre, that you are basically not sick (GREEN 2019, 10)

Together, these comments foreground the additional economic value generated from engaging dis/abled people in the arts, for its reduction of the care costs required for this group. Moomsteatern's language reveals a disciplinarian attitude stemming from a particular history of theatre practice in which actors require an extremely high level of personal health and self-care. This is used as a means to promote similar behaviour to a social group who may be less able to initiate this standard on their own.

Between the three primary organisations, there is a difference in the use of organisational form as a descriptor for identity. Breathe Magic describe themselves as 'a not-for-profit social enterprise company that span out of Guys and St Thomas's charity' (GREEN 2019, 5), highlighting a form whose history is that of a singular project, based in a hospital, replanted into the new context of being a service provider to NHS trusts. For Moomsteatern, organisational form is used to re-enforce the autonomy of the venture: as they explain, 'the only way that we would ensure our independency' (GREEN 2019, 21). This is qualified, in more detail, by a correlative relationship between funding stream and influence on the workings of the organisation, given that it is 'more difficult to apply for some of the larger fundings, and it means that for instance the funders can have a lot more influence on what you're doing' (GREEN 2019, 21). Regional funders are seen to take a 'big responsibility' and be those primarily interested in the artistic nature of the work (GREEN 2019, 22). The juxtaposition of the 'influence' of funders and the 'interest' of funders reveals a tension between how the organisation's work is valued, and how much this valuation brings with it certain responsibilities (to adhere to the directives of a funder). 


\section{Holistic Views of Health}

A recurrent theme of these three organisations is their focus on a more holistic view of health in which physical and mental health are seen as interdependent. Breathe Magic describe their programme of increased mobility through magic as "holistic" to the extent that mental and physical health are 'interlinked' (GREEN 2019, 6). This is justified on the basis of research which suggests $44 \%$ of young people with this condition suffer mental health and psychological issue (GREEN 2019, 5).

Shown from another side by Moomsteatern, the uncreative and static nature of the care system for people with intellectual dis/abilities is seen to produce additional physical symptoms, that 'if you don't have anything to do - you're not satisfied physically, intellectually - then you get sick' (GREEN 2019, 10). This statement unites persons with intellectual dis/abilities together with those who (in Moomsteatern's words) are 'statistically normal': the causal relationship between mental health, wellbeing and physical health is a theme of public health concerns in general. This was obviously a common theme throughout the Arts and Health conference, which highlighted activities such as dance as 'a mental activity as well as a physical one' (GREEN 2019, 42).

TeaterInterakt have created productions which showcase in hospitals and health institutions, sometimes based on the experiences of patients on long-term mental health units. Their comment reflects a binary between medicinal approaches to treatment and cultural/social approaches:

it's very different if there [are] different places on psychology hospitals in Sweden. But on this, they had no therapists they had no terapeuter [therapists] they just had medicine [...] it was no art at all [...] Before, in Sweden, they had that you can make food, you can work in the garden as a psychiatric patient [...] They have taken everything of this away in Swedish hospital for psychiatry (GREEN 2019, 33).

Practices which combine skill, creativity and some physical activity - such as gardening or cooking - are side-lined, in this account of psychiatric care, in favour of a more traditionally medicinal view of how to treat such patients. 
This cultural and practical element of care is also flagged by Moomsteatern from a preventative perspective:

Because if you say that you will provide an arena for a person with an intellectual dis/ability to live a good life, then you have to, to bring in the health issues as well. Maybe you have some diagnosis that [...] makes people unaware of "what can I eat, what can I not eat'. And who is respon[sible]? (GREEN 2019, 12).

In this account, one's state of health is maintained by practices, habits and activities such as eating - and the accountability of which professional body should oversee this is in question. This preventative approach reflects concerns within public health more generally, as it is often a responsibility of government and education to instil these habits. Yet, as will be explored later, organisations like Moomsteatern provide a role which potentially implicates them in such responsibilities of care.

\section{The Role of Intermediaries}

Against the backdrop of 'gaps' between systems, all three organisations acknowledge the significance of individual agents, or roles, able to move between these systems - bridging the requirements of social care, funding providers and the individual experiences of dis/abled people.

In the case of Breathe Magic, the 'intermediary' is able to replace the need for another professional to deliver the core service, with a different set of skills. A similar linkage was flagged at the Arts and Health Conference, in the introduction of a 'link worker' between social prescribers and patients (GREEN 2019, 43). These figures have a community knowledge of activities, and are not necessarily medically trained. In recognising that the children they work with required intensive therapy, Breathe Magic acknowledge: 'the NHS don't have the resources to be able to free up a whole load of therapists to be able to deliver 60 hours of intensive therapy' (GREEN 2019, 5-6). Instead, this therapeutic role is filled by occupational therapists and magicians.

For Moomsteatern and TeaterInterakt, the power of existing intermediaries within systems is relied upon, but constructively critiqued. Moomsteatern explain a project they are engaged with which aims to 'educate the educators' by focussing on the impact of 
leaders for actualising participation (GREEN 2019, 25). Despite trepidation about daily activity centres, Moomsteatern identify the fundamental importance of engaging with the perspectives of leaders within them. The aims appear to be to address how an institutional view on the limitations of people with intellectual dis/abilities may constitute the care in a way that does not promote independence or relies too heavily on the perceived limitations of what people with dis/abilities can achieve.

The lack of training identified, coupled with the idea of Moomsteatern as a knowledge source, echo the perceived gap between cultural and social-or-care-based approaches to supporting people with intellectual dis/abilities. In other words: training may exist within the social sector for this group (reflecting the emphasis on care over self-reliance), and training exists within the arts sector in general, but Moomsteatern are unique in combining the pedagogies of both. Their role here is also as an intermediary, reinforcing their validity in training pedagogues who occupy a similar role.

TeaterInterakt recall an experience of working with vulnerable people and the conservative expectations of their carers at that time. They recollect, in relation to one woman with autism:

'[She] would jump up and down, up and down, and just screaming, and the caretaker were rather "Are you going to have her in the performance? Is this a good idea?" Then I gave her a big - not like this it was made of bamboo or something - that she had it on her head, like this, with full of scarves in beautiful colors. So she was one of those who walking on the square selling this - you know in the play - and she came in like a queen with this on her head. And to the music, accepted the rhythm of the music, and put it down, and she showed up all her sleeves in the beautiful colors. She was just wonderful...' (GREEN 2019, 30-31).

In this anecdote, once again the representatives of the social care system are seen as more overtly cautious about the involvement of their charges, and those involved in the creative industries are portrayed as those who connect their criteria for expression (performing with the coloured scarves, moving to the music) with the vulnerable person.

\section{Care in the Health System}


The case organisations interact with the healthcare system to different extents - whether in the relationship between 'the inside of the patient and outside forming of the hospital' (GREEN 2019, 34) for TeaterInterakt, or through initiating 'pilot studies' (GREEN 2019, 5) which develop new therapeutic delivery models, in the case of Breathe Magic.

Moomsteatern and TeaterInterakt demonstrate more thematic interactions with the healthcare system, investigating how institutional constructions of 'care' might be challenged for vulnerable people. TeaterInterakt construct performances with longer research periods for this group - more than 6 weeks (GREEN 2019, 32) - and identify problems such as the inconsistency of professionals (for patients returning to hospital). They summarise this in the following:

If you come in once to the hospital you get a contact person. But if you are there in four weeks, and you go home in four weeks, and you have a breakdown again and come back, you don't get the same, although you're in the same hospital, in the same place, exactly. You don't get the same contact person so you have to tell the story all over again (GREEN 2019, 34).

These reflections are augmented with organisational critiques of situational conditions that they perceive in healthcare, such as the mixing of patients with incompatible conditions and treatment needs:

[the hospital ward] was overloaded with people, mixing people that had bipolär [bipolar disorder] or depression or mild-psychotic. They mix everybody together. I mean, it was a lot, it was young girl in 16 being there and an old woman who was dement [had dementia] (GREEN 2019, 34).

In this latter example, there is a clear sensitivity identified by the co-mingling of patients - a quality also highlighted by an organisation working with dance and Parkinson's disease, at the Arts and Health conference. Attendees heard from a man who, after being offered initial 'social' encounters with other people who had Parkinson's disease, soon after diagnosis, he 'did not want to go to the support group for fear of seeing his future self" (GREEN 2019, 42), at a more distressing level of physical dis/ability. The artistic intervention - learning dance with other people with Parkinson's disease - yielded more positive reflections. 


\section{Analysis: Disrupting Systems}

The following cross-cutting themes will now be discussed in relation to kynicism, models of dis/ability, and systemic social innovation. These are: Care and Safety, Bodies, Experise, and Speech.

\section{Care and Safety}

The organisational attitude, or a pedagogy, of Moomsteatern in relation to 'care' has a constant stridency to it - as they comment: 'We push it a lot, all the time, all the time, all the time, all the time' (GREEN 2019, 12). The robustness of this approach is directed toward the gradual accumulation of independence, and the continual acknowledgement by Moomsteatern that these disciplinary standards are more to do with being a theatre, than being wedded to a standard care narrative. Comments from the Arts and Health conference make for fruitful contextualization here: top health practitioners speak of an emergent theme of 'frailty - the loss of resilience' (GREEN 2019, 43) in vulnerable patients, particular those in older age. Addressing the 'frailty narrative' (GREEN 2019, 43) is described as a UK occupation, and whilst comparisons should be very carefully approached between persons with intellectual dis/abilities and older people in general, the notion of resilience comparably connotes taking a more robust approach at developing personal self-sufficiency. Resiliency necessarily involves building the capabilities to adapt and respond to change, potentially stress-testing the boundaries of the asset. Despite the impersonality of this language (when, in this context, the resilient 'asset' is a potentially vulnerable human being) Moomsteatern's drive to push their actors into both a 'safe and scared' (GREEN 2019, 28) position hints at this same directive.

Moomsteatern also re-assert the importance of 'failure' to the experience of persons with intellectual dis/abilities, which is seen as a provocative concept to a social care system which does not 'allow' this group to fail. Arguably, the development of this quality can be seen in the lineage of dis/ability as a predominantly biological issue, to be dealt with by the medical profession, to further perspectives such as the 'independent living' model (Phillips 2001, 197) pioneered in the US as a form of community support. 
Healthcare, as a site for managing this group, and as a complex adaptive system, has been shown to have its own complicated relationship with 'failure' (Hollnagel et al., 2015) largely resisting and stigmatising failure, despite the rarity and necessarily unpredictability of hazards. This is not to say that striving for the fewest incidents is an unreasonable aim (in a system where 'failure' can mean patient death) but, as writers in safety science have argued, aspiring toward 'zero' incidents often goes hand-in-hand with a lack of trust in health professionals, and an inability to institutionally deal with failures when they (inevitably) happen (Decker 2017).

Kynicism emphasises that for 'the human being who exemplifies the love of truth and conscious living, life and doctrine must be in harmony' (Sloterdijk 1987, 101). This identified that philosophers had typically preached a more idealist worldview which did not accord with the realities of life's fallibilities. Moomsteatern's pedagogy of challenging the power dynamics in 'care' relationships, and the incorporation of failure, suggests an interest in bringing the less enamoured qualities of life (being scared, failing etc.) more in tune with the organisational practices that involve persons with intellectual dis/abilities. This constitutes a modern version of doctrine to the extent that organisations are infused with certain values and promote these through their actions.

This approach appears to be at the forefront of thought leadership of Arts and Health. Whilst conversations during the 2018 AeSop conference featured health professionals advising that new innovations 'always have side effects' (GREEN 2019, 43), with failure part of this process, much of the language still approached failure in the context of terms such as 'human factors' (GREEN 2019, 43). The 'human factors' paradigm emphasises the regulation of individual behaviour within complex systems (Dekker 2002) to prevent them from doing things incorrectly. 'Failure' here is not seen as an inevitable feature of work, an inherent human fallibility, but is rather seen as the result of deviants. Whilst it is interesting that some paradigms of complex systems management are entering into conversation with the arts (via. new collaborations with healthcare) Moomsteatern's more brazen assertion of these particular rights for persons with intellectual dis/abilities suggests that they are moving these conversations toward more resilient conceptions of 'care' and 'safety'. 


\section{Bodies}

Separations of public and private have historically been used to disqualify the experiences of dis/abled people, particularly when private spaces have been inaccessible or custom has re-enforced that certain actions should not occur in public spaces. Exposing these conditions is known as the '[s]ocial barriers approach' (Goodley 2014, p.11) to dis/ability. Moomsteatern's performances feature bodies who are treated as actors, requiring a commitment that potentially transgresses the typical customs of public and private space: the Artistic Director recall actors having flu, placing 'buckets all around outside the stage, and then they go out, play and [sound of person being sick]' (GREEN 2019, 11). The presentation of bodily processes like these, in public space, echoes the kynic desire to 'challenge the public sphere' (Sloterdijk 1987, 105) on the basis that 'it is the only place in which the overcoming of idealist arrogance can be meaningfully demonstrated' (Sloterdijk 1987, 105). 'Idealism' here connotes a kind of unity and the suppression of more sensual experiences of life, which appears to come from the same focus on biomedical notions of the body that the social model of dis/ability emerged against. By disrupting this venture, Moomsteatern re-instate the significance of bodies in general with their whole constitution - but also the particular significance of bodily repression for a group who have not been given the space to 'tell their story, the journey of their body' (Phillips 2001, 206).

Breathe Magic's work responds to the opposite dilemma: how can privacy be reestablished for dis/abled people who have required help to perform intimate tasks? In the example of the young child who is able to use a toilet alone as a result of the intensive therapy (GREEN 2019, 6), autonomy is gained by the integration of performance into mobility exercises. There is a less obvious kynical dimension to this, yet the return of bodily autonomy is predicated on viewing not only the impairments of a physical body, but: 'an understanding body, mental perceptions and social experiences as an integrated whole' (Priebe and Sager, in Sigurdson et al. 2015, 59).

In these accounts of innovation using the performing arts, the right of dis/abled people to take part in the creation of public/private norms is foregrounded, but reveals tensions between different models of dis/ability. Moomsteatern's example seems more typical of the social model - in which physical or mental impairments are translated into 'dis/abilities' by society's inadequate arrangements. Moomsteatern show-up these 
barriers and remove them: actors may have wheelchairs on stage if they are injured (GREEN 2019, 11), as this is just another requirement needed for the person to perform. Breathe Magic, however, operate with a slightly more "affirmative" model - where dis/ability is acknowledged as an experience of the child, and they are supported to become as autonomous as possible in response.

The division between these models of dis/ability provides new perspectives on narratives of innovation. Are the 'problems' around dis/ability best seen as barriers within society, or should the focus be more coherently on the management of impairments themselves? The tensions here represent what Roman refers to as the 'unruly form, conscience and commitment' (Roman 2009, 668) of bodily divisions within dis/ability studies. There is further 'unruly' irony, for instance, in the justification that Breathe Magic operate on a more affirmative model due to the fact that the condition they manage (hemiplegia) is potentially not a permanent impairment and can be alleviated. Yet, to even conceptualise dis/ability in this way casts it as a physiological issue to be managed or 'cured', rather than as a way in which society dis-avows certain physical or mental states (on a more social model).

Whichever models are being implicitly demonstrated by these organisations, all three ground these in a fundamentally holistic conception of 'health'. The divisions of mental/physical, medical/socio-cultural and even prevention/cure are taken to task through (1) acknowledging mental health side-effects to physical therapy, (2) highlighting the lack of social activities for patients through performance, and (3) using the requirements of working in the theatre profession to explore the responsibly the state has for inspiring positive health choices. These techniques challenge the relationship between individuals and health systems by pushing back against processes of organizing which re-enforce these divisions. By re-inscribing the significance of the whole body including its private processes - the organisations follow the kynical credo that 'it takes cheek to say what is lived' (Sloterdijk 1989, 102), rather than attempting to live-out airbrushed ideals.

Planting Sloterdijk's work into organisational theory, a weak version of kynicism may be found in simply bringing complex systems more in line with the realities of those of live, work or participate in them. Complex systems have been argued (Dekker 2011) to operate in line with more idealist features, such as procedures designed rationally to 
accurately guide a job to unassailable completion. Societal systems that must accommodate a large number of participants (at the highest end, public systems like healthcare) use processes of 'labelling' to quickly establish 'what things are', rather than metaphors which say 'how things are' (Czarniawska-Joerges and Joerges 1990, in Weick $2001,20)$ and establish relationships. In theatrically and pragmatically making the case for the dissolution of divisions in health around dis/ability, these three arts organisations become more in line with 'person-centric' approaches, which work from the interdependency of social, cultural and physical factors in patients.

\section{Expertise}

In Breathe Magic's speech, the child is affirmed as an 'expert' (GREEN 2019, 6) who is required to perform a magic trick in front of an audience. The 'expertise' being acknowledged here is the acquired physical skill to perform the trick, the length of time spent developing the trick, and a knowledge of the mechanics of the trick that constitute the 'mystery' (GREEN 2019, 7) that the child will display. What is particularly striking about magic in this context is that the live performance of the art - unlike, for example, singing - requires a concealment as well as a display. As an audience, we are not told "how it is done"; this knowledge belongs to the performer who, in this case, lives with a physical condition that ordinarily sets them at a disadvantage compared to others in what they can achieve.

From a kynicist perspective, performance is used here to re-install the body as a repository of a skill, and thus a site for knowledge. In another expression of skill valuation, a performance of The Jungle Book features the protagonist, Mowgli, played by a 'statistically normal actor'. It is explained that: 'he was basically disabled because all the other animals is played by dis/abled actors, where on their home arena. That was our way of telling the story'. (GREEN 2019, 16). In this example, the stage space itself is transformed into a landscape where the group ordinarily stigmatised are those with superior navigational knowledge. Through both these examples of expertise, Allan's notion of kynicism as 'productive ideology' (Allan 2004, 32) for dis/ability arts is evoked.

By creating situations in which the 'expert' is seen to be someone who is ordinarily not acknowledged as an expert, the contingency of social strictures becomes 
apparent. Why would a dis/abled child not be seen as a strong magician, particularly considering their more acute relationship with their body through sustaining an impairment? This pushes beyond the social innovation mantra (discussed above in relation to the Social Model of Disability) that drawing on the skills of marginalized people is useful because of personal capacity to solve one's own problems (Mulgan 2006, 150), and instead seeks parity of expertise for dis/abled people in areas beyond their own situations.

\section{Speech}

Moomsteatern acknowledge power relationships in how temporarily able-bodied people generally interact with persons with intellectual dis/abilities, and use performance to translate this into the inverse relationship of 'senders' and 'receivers'. Audiences, they argue, 'want to be senders back, because that's the way to treat a person with dis/ability' (GREEN 2019, 15) - this is countered by encouraging them to 'to experience or learn something, from a person who is, outside the theatre, is living a very marginalized life' (GREEN 2019, 15). The challenging of this power relationship is also given visualisation in castings within the stage-world (as in the situation of Mowgli, above).

The kynicist elements of these interactions are the sense that sensuous bodily expression is 'a kind of argumentation' (Sloterdijk 1987, 101) against the expectations Moomsteatern understand their audience to have, and that the actions of thinking and validating this group are not 'limited to the head' (Sloterdijk 1987, 102). Bodies perform this argumentation, by being cast in a role, or in navigating the stage-space as a site of familiarity. Audiences, by contrast, are able to see the familiar-ity of the space as a construction, analogous to the structure of their own society as shaped by the abilities of those who are not dis/abled (Larsson 2006, 162). In other words: any sense of an inherent superiority of a temporarily able-bodied perspective is radically contextualised. Such a use of the arts for this purpose - a kind of public education - echoes but twists Sigurdson's assertion that the arts combine: 'the whole, the personal, the familiar and the foreign ... to alleviate the effects of fragmentation and alienation' (Sigurdson et al. 2015, 60-61). Rather, that which is 'familiar' or 'foreign' are presented as merely viewpoints, and any 
estrangement felt by the audience in response is precisely generated by the use of the arts to reveal the contingency of society's collective perspectives.

\section{Conclusion}

These dis/ability arts organisations sit not only between the traditional spheres of social innovation analysis (the public, private and civil sectors) but at the intersection of new movements of scholarship and practice - such as Arts Entrepreneurship, and the Arts and Health movement. Categorization for this group is a challenge: the organizations draw from a mixture of aesthetic and commercial practices - of 'reinventing' markets or being a 'game-changer' (GREEN 2019, 41) to established markets. Yet, they are beset with tensions of the co-option of art-practices into health promotion and social projects.

Dis/ability, whilst a compelling subject for the developments of technologies of empowerment, continues to be approached from the standpoint of individual innovations which appear to have little systemic critique, or fail to question the wider responsibilities of an ableist culture. Organisations which diverge from product-based innovation and individualism approach dis/ability through the inherently collective and representational activity of live, performing arts. These organizations operate within and actively connect many systems: the welfare system, the health system, the arts sector and their local audience bases. Their operations clearly have the potential to influence and refract established norms of institutions, yet the State sector appears to struggle with valuing their straddling of techniques to connect dis/ability to public life.

Whilst the arts has long been used in health settings, increasing interest in "holistic" forms of health appear to have provided a language of expression for combining the live, active, immersive experience of performance with therapeutic recovery, or longterm care settings. This paper has attempted to show some of the ways in which a "holistic" health approach is manifest in dis/ability arts - in acknowledging the health concerns of performers, in focussing on the social aspects of wellbeing, and re-inscribing the body as a site for knowledge and valid experience. Yet, in more defiant approaches to the work integration of dis/abled people through the arts, these case study organisations have cast doubt on aspects of the health and social care sector: the lack of imaginative resources for dis/abled people to live a creative life, the conservative attitude of 
pedagogues, and the tensions between a public service "for all" and the specific requirements of people who need bespoke care.

Many of these tensions stem from the complex nature of social systems, and thus this project attempted to plot ways in which these could be negotiated, or resisted. Theatres embody this tension: their organizational ontology begs the question "Are theatres best defined by business-traditional features like a commercial drive, with roles and responsibilities, or as aesthetic spaces with an inherently representational nature which affects "who performs", "who is heard", and "who has power"? It may be, in idealistic sides of the field, that an entrepreneur 'will never stick to one version of her "truth" (de Leeuw 1999, 263), but this becomes hugely more difficult when conceptualizing 'systemic innovation'. More acutely than any other innovation, systemic innovation works with complexity, scale, interconnection and extensive institutional history. Differences in the language of systems was particularly acute in the theme that emerged of falling between cultural and social funding, equally challenging as the 'bind' of evidence and funding that sits within the health sector.

Many conclusions from this study concern the myriad ways dis/ability arts organizations disrupt how dis/abled people are epistemically valued (how people within this group are represented, acknowledged as experts, taken seriously as innovators rather than thankful recipients of jobs in social enterprises etc.). These qualities require further exploration in the social entrepreneurship field; this study drew on the language of aesthetics to frame the value of these representational qualities, but alternative approaches seem crucial for living up to the true richness of 'systemic' as an innovation-type involving marginalized groups.

\section{Future Research}

Research into the emotional qualities of entrepreneurial value (Goss 2008), and the 'performativity' (Mauksch 2018) or event-like nature of social innovations, suggest an increasing interest in drawing from the epistemic and productive processes within arts scholarship. Further work could ensure that concepts like 'performance' do not become too diluted when applied to social innovation: for example, to ensure that defining a 'performance economy' (Stratan 2017) also provokes interest in who performs, what 
infrastructural conditions regulate this performance, and how might these conditions be suppressing certain knowledge claims in an ableist culture.

Future research connecting dis/ability studies with social innovation should, as this paper has argued, broaden its scope from the WISE model. Even while interventions such as the Social Model of Disability grow in influence, the assumption that dis/ability is still a personal issue, a 'biomedical' matter, has already framed legitimate choices of research subject and may discredit focusses on organisations which do not fit a clear mould. Studies such as McLoughlin et al. (2018), for example, provide strong contemporary analysis of digital platform co-operation in the disability care sector, yet the organisation Moomsteatern has been shown to actively resist being labelled a 'disability arts' organization, in favour of a model which focuses on collegiate rather than caring relations. A future typology of classifications would be appropriate, when the social entrepreneurship field has matured its research on disability, to accommodate initiatives like these which resist certain definitional categories of research, and whose innovation occurs co-productivity behind-the-scenes.

Systemic innovations, Murray et al. note, are often 'suddenly pushed forward by a crisis or a disruptive technology' $(2010,108)$. The challenge for system-wide research is this area is that a 'crisis' for dis/ability may not show itself in the traditional sense. Forms of epistemic occlusion and representational bias continue to severely restrict the livelihoods of dis/abled people, but opening up research paradigms to include a broader range of organisations and expressions of 'innovation' will engender more complex and epistemically-just studies. 
Words: 10,544

Acknowledgements

The author would like to thank Lisa Maurer Chodorkoff (Roskilde University) for her supervision during the research process, as well as the two anonymous reviewers who thoughtfully steered the text forward.

Disclosure Statement

No potential conflict of interest was reported by the author.

\section{References}

Allan, Julie. 2005. 'Encounters with Exclusion through Disability Arts'. Journal of Research in Special Educational Needs 5, no. 1: 31-36.

— 2004. 'The Aesthetics of Disability as Ideological Critique'. Counterpoints 270, no. Ideology and the Politics of (In)Exclusion : 32-45.

Amit, Gilead. 'Welcome to Biscuit Land'. New Scientist 228, no. 3048 (November 2015): 27. https://doi.org/10.1016/S0262-4079(15)31661-4.

Aston, Jodie. 2018. 'Hospital Arts Co-Ordinators: An Accidental Profession?' Wellcome Trust. Accessed 2 September 2018. 
https://www.artshealthandwellbeing.org.uk/resources/research/hospital-arts-coordinators-accidental-profession.

Barinaga, Ester. 2013. 'Politicising Social Entrepreneurship - Three Social Entrepreneurial Rationalities Toward Social Change'. Journal of Social Entrepreneurship 4, no. 3 (November 2013): 347-72. https://doi.org/10.1080/19420676.2013.823100.

Bishop, Claire. 2012. Artificial Hells: Participatory Art and the Politics of Spectatorship. Verso Books.

Breathe AEHR. 2016. 'Breathe Magic for Hemiplegia: Information Pack for GPs and Clinical Commissioning Groups (CCGs)', March 2016. http://breatheahr.org/wpcontent/uploads/2016/03/Breathe-Magic-Overview.pdf.

Brown, Ralph. 2005. 'Performing Arts Creative Enterprise: Approaches to Promoting Entrepreneurship in Arts Higher Education'. Entrepreneurship and Innovation, August 2005, 159-67.

Cancellieri, G, G Cappellaro, A Turrini, N Salido-Andres, M.J. Sanzo Perez, L.I. Alvarez Gonzalez, M Rey-Garcia, et al. 2016. 'Social Innovation in Arts \& Culture Social Cohesion in Contexts of Culture-Led Place Rejuvenation. (Deliverable 4.3 of the Project: "Impact of the Third Sector as Social Innovation" (ITSSOIN)'. European Commission - 7th Framework Programme, 8 October 2016. 
Clark, Thomas, and Julie Stewart. 2012. 'Teaching Social Entrepreneurship: Arts Management with a Community Perspective'. Journal of Entrepreneurship Education 15 , no. SI.

Davies, Anna, Geoff Mulgan, Will Norman, Louise Pulford, Robert Patrick, and Julie Simon. 2012. ‘Systemic Innovation’. Social Innovation Europe, December 2012.

De Ruysscher, C., C. Claes, T. Lee, F. Cui, J. Van Loon, J. De Maeyer, and R. Schalock. 'A Systems Approach to Social Entrepreneurship'. VOLUNTAS: International Journal of Voluntary and Nonprofit Organizations 28, no. 6 (December 2017): 2530-45. https://doi.org/10.1007/s11266-016-9704-5.

Dekker, Sidney. 2002. 'Reconstructing Human Contributions to Accidents: The New View on Error and Performance'. Journal of Safety Research 33, no. 3: 371-85.

2011. 'What Is Rational about Killing a Patient with an Overdose? Enlightenment, Continental Philosophy and the Role of the Human Subject in System Failure'. Safety Science 54, no. 8 (August 2011): 679-83.

Denzin, Norman, K, and Yvonna Lincoln S. 1994. Strategies of Qualitative Inquiry. SAGE Publications Inc..

Dey, Pascal. The Symbolic Violence of 'Social Entrepreneurship': Oxford: 3rd Research colloquium on social entrepreneurship, 2010. 
Disability Peoples International. "Constitution of Disabled People's International." Constitution (blog), 2012.

Dooris, Mark. 2005. 'A Qualitative Review of Walsall Arts into Health Partnership'. Health Education 105, no. 5 (2005): 355-73.

Fancourt, Daisy. 2016. 'Magic as Medicine for Children with Hemiplegia'. Evidently Cochrane (blog), 14 October 2016. http://www.evidentlycochrane.net/magic-medicinechildren-hemiplegia/.

Gidron, Benjamin. 2014. 'Market-Oriented Social Enterprises Employing People with Disabilities: A Participants' Perspective'. Journal of Social Entrepreneurship 5, no. 1 (2 January 2014): 60-76. https://doi.org/10.1080/19420676.2013.829116.

Goddard, Jennifer. 2018. 'Valuing the Place of Young People with Learning Disabilities in the Arts'. In Valuing Disabled Children and Young People: Research, Policy, and Practice. Place of publication not identified: ROUTLEDGE, 2018.

Goodley, Dan. 2014. Dis/Ability Studies: Theorising Disablism and Ableism. New York: Taylor \& Francis.

Goss, David. 'Enterprise Ritual: A Theory of Entrepreneurial Emotion and Exchange'. British Journal of Management 19, no. 2 (June 2008): 120-37. https://doi.org/10.1111/j.1467-8551.2006.00518.x.

Green, Kai Roland. 2019. "Dis/ability Arts Social Enterprise: A Model for Systemic Innovation in the UK and Sweden" (dataset). OSFHome Depository. 
https://osf.io/yafc2/?view_only=1393272d6fa54ace9873336ddebaa2f8

Harvie, Jen. 2013. Fair Play: Art, Performance and Neoliberalism. 1st ed. UK: Palgrave MacMillan UK.

Hollnagel, Professor Erik, Professor Jeffrey Braithwaite, and Professor Robert L. Wears. 2013. Resilient Health Care. Ashgate Publishing, Ltd.

Jackson, Shannon. 2011. Social Works: Performing Arts, Supporting Politics. Oxon: Routledge.

Jacobi, Nadia von, and Enrica Chiappero-Martinetti. 2017. 'Social Innovation, Individuals and Societies: An Empirical Investigation of Multi-Layered Effects'. Journal of Social Entrepreneurship 8, no. 3 (2 September 2017): 271-301.

https://doi.org/10.1080/19420676.2017.1364288.

Jensen, Anita, Theodore Stickley, and Alison Edgley. 2016. 'The Perspectives of People Who Use Mental Health Services Engaging with Arts and Cultural Activities'. Mental Health and Social Inclusion 20, no. 3 (2016): 180-86.

Kitching, John. 2014. 'Entrepreneurship and Self-Employment By People With Disabilities'. OECD, Background Paper for the OECD Project on Inclusive Entrepreneurship. 
Kovalainen, Anne, and Johanna Österberg-Högstedt. 2013. 'Entrepreneurship within Social and Health Care: A Question of Identity, Gender and Professionalism'. International Journal of Gender and Entrepreneurship 5, no. 1 (2013): 17-35.

Kuppers, Petra. 2011. Disability Culture and Community Performance: Find a Strange and Twisted Shape. Palgrave MacMillan UK.

Larsson, Stig. 2006. 'Disability Management and Entrepreneurship: Results From a Nationwide Study in Sweden'. International Journal of Disability Management Research 1, no. 1: 159-68.

Macnaughton, Jane, Mike White, and Rosie Stacy. 2005. 'Researching the Benefits of Arts in Health'. Health Education 106, no. 5: 332-39.

Mauksch, Stefanie. 2018. '(It) Is Exactly What It Was In Me' - The Performativity Of Social Entrepreneurship' in Dey, Pascal and Chris Stevaert, Social Entrepreneurship: An Affirmative Critique. Edward Elgar Publishing

McLoughlin, Ian, Yolande McNicoll, Aviva Beecher Kelk, James Cornford, and Kelly Hutchinson. 'A “Tripadvisor" for Disability? Social Enterprise and "Digital Disruption" in Australia'. Information, Communication \& Society 22, no. 4 (21 March 2019): 52137. https://doi.org/10.1080/1369118X.2018.1538382.

Medina, José. 2013. The Epistemology of Resistance: Gender and Racial Oppression, Epistemic Injustic, and Resistant Imaginations. Oxford, UK: Oxford University Press. 
Moomsteatern. 2012. 'MOOMSTEATERN (Booklet)'.

Mulgan, Geoff. 2006. ‘The Process of Social Innovation'. Innovations: Technology, Governance, Globalization 1, no. 2 (1 April 2006): 145-62. https://doi.org/10.1162/itgg.2006.1.2.145.

Murray, Robin, Julie Caulier-Grice, and Geoff Mulgan. 2010. 'The Open Book of Social Innovation'. The Young Foundation.

Newey, Lance R. 2018. “"Changing the System”: Compensatory versus Transformative Social Entrepreneurship'. Journal of Social Entrepreneurship 9, no. 1 (2 January 2018): 13-30. https://doi.org/10.1080/19420676.2017.1408671.

Onyx, Jenny, Simon Darcy, Simone Grabowski, Jenny Green, and Hazel Maxwell. 2018. 'Researching the Social Impact of Arts and Disability: Applying a New Empirical Tool and Method'. VOLUNTAS: International Journal of Voluntary and Nonprofit Organizations, 20 February 2018.

Parkinson, Clive, and Mark White. 2013. 'Inequalities, the Arts and Public Health: Towards an International Conversation'. Arts \& Health 5, no. 3 (2013): 177-89.

Phillips, Cassandra. 2001. 'Re-Imagining the (Dis)Abled Body'. Journal of Medical Humanities 22, no. 3 (2001): 195-208. 
Ponelis, Shana R. 2015. 'Using Interpretive Qualitative Case Studies for Exploratory Research in Doctoral Studies: A Case of Information Systems Research in Small and Medium Enterprises', no. 10 (2015): 353-550.

Quilley, Stephen. 2012. 'System Innovation and a New "Great Transformation": ReEmbedding Economic Life in the Context of "De-Growth". Journal of Social Entrepreneurship 3, no. 2 (1 October 2012): 206-29. https://doi.org/10.1080/19420676.2012.725823.

Roman, Leslie G. 2009. 'Disability Arts and Culture as Public Pedagogy'. International Journal of Inclusive Education 13, no. 7 (1 November 2009): 667-75. https://doi.org/10.1080/13603110903041912.

Sigurdson, Ola, Gunilla Priebe, Morten Sager, Katarina Bernhardsson, and Daniel Brodén. 2015. Culture and Health : A Wider Horizon. Department of Literature, History of Ideas, and Religion, University of Gothenburg, 2015. https://gupea.ub.gu.se/handle/2077/40177.

Sloterdijk, Peter. Critique of Cynical Reason. Translated by Michael Eldred. 9th ed. Minnesota: University of Minnesota Press, 1987.

Social Prescribing Network. 2016. 'Report on the Annual Social Prescribing Network Conference', 20 January 2016. https://www.westminster.ac.uk/file/52171/download. 
Stratan, Dumitru. 'Success Factors of Sustainable Enterprises Through Circular Economy Perspective'. Visegrad Journal of Bioeconomy and Sustainable Development 6 (2017).

Svensson, Peter, and Lars Bengtsson. 2010. 'Users' Influence in Social-Service Innovations: Two Swedish Case Studies'. Journal of Social Entrepreneurship 1, no. 2 (2010): 190212. https://doi.org/10.1080/19420676.2010.511813.

Teater InterAkt. 'Bakrund', n.d. http://teaterinterakt.se/bakgrund/.

Todd, Bella. 2016. 'Crossing The Line Festival: Leaping Over Barriers'. Disability Arts International, British Council (blog): http://www.disabilityartsinternational.org/blogs/2017/crossing-the-line-festival-leapingover-barriers/.

Tussy, Maria, Carla Bonino, and Fundación ONCE. 2015. 'European Award for Social Entrepreneurship and Disability: Promoting Social Investment'. csr+d: european network for corporate social responsibility and disability, 15 December 2015. https://csr-d.eu/en/csrd-outcomes/.

Weick, Karl. Making Sense of the Organization. Oxford, UK: Blackwell Publishing, 2001. 
Data Availability Statement

The data that support the findings of this study are available on request from the corresponding author, (GREEN). The data is not publicly available due to restrictions requested by some participants in the study.

Within the data available upon request, some sections of data are not available, on request from participants in the study. This is due to time and professional position changes between the interview and final publication of the journal paper. 